\title{
Abdominal Imaging 2014
}

\author{
C. Daniel Johnson \\ Department of Radiology, Mayo Clinic, Scottsdale, AZ 85259, USA
}

This April issue of Abdominal Imaging marks the second issue of 2014 under "new management." It is an honor to be named the new Editor-in-Chief of the Journal succeeding the esteemed Morton Meyers, MD. The purpose of this communication is to provide the readers with some insight into my vision for the Journal and its future direction.

As the official journal of the Society of Abdominal Radiologists (SAR), we want to facilitate a shared vision for the Journal. Addressing all of the professional needs of the abdominal radiologist will be our overarching goal. These needs are challenging, but can be accomplished in concert with the SAR and other abdominal imaging societies. The heart and soul of the Journal will be maintained by promoting and publishing high quality, peer-reviewed research as our number one priority. We intend to continue a global outreach to abdominal imagers.

Secondarily, we hope to grow in the following areas: publishing on current practice issues or new standards of care including process quality improvement (PQI) (practice section), preparing for a first time or recertifying examination (review articles), and reaching readers via social media as an alert to articles of special interest. We are likely to de-emphasize case report publications over time.

Abdominal imagers are encouraged to submit their best work to the Journal. An all-star cast of associate editors, in various sub-disciplines of abdominal imaging, have been assembled to filter reviewer feedback and mentor authors. These editors depend upon the gracious volunteer effort of countless reviewers. If you are interested in helping us review articles, please contact me or an associate editor (listed on our masthead). We hope over time to provide just the right amount of coaching to create the best scientific publications while respecting author's time and independent thought.

With your help, I look forward to the future growth of the Journal. We will strive to keep the Journal relevant and to meet your professional needs.

Correspondence to: C. Daniel Johnson; e-mail: johnson.daniel2@mayo.edu 